\title{
The National Weight Control Registry: Is it Useful in Helping Deal with Our Obesity Epidemic?
}

\author{
James O. Hill, PhD ${ }^{1}$; Holly Wyatt, MD ${ }^{1}$; Suzanne Phelan, PhD²; Rena Wing, PhD 2 \\ ${ }^{1}$ Center for Human Nutrition, University of Colorado Health Sciences Center, Denver, Colorado; \\ ${ }^{2}$ The Miriam Hospital, Brown University, Providence, Rhode Island
}

\begin{abstract}
The National Weight Control Registry (NWCR) consists of over 4800 individuals who have been successful in longterm weight loss maintenance. The purpose of establishing the NWCR was to identify the common characteristics of those who succeed in long-term weight loss maintenance. We found very little similarity in how these individuals lost weight but some common behaviors in how they are keeping their weight off. To maintain their weight loss NWCR participants report eating a relatively low-fat diet, eating breakfast almost every day, weighing themselves regularly, and engaging in high levels (about 1 hour/day) of physical activity. Because this is not a random sample of those who attempt weight loss, the results have limited generalizability to the entire population of overweight and obese individuals. The value of this project lies in identifying potential strategies that may help others be more successful in keeping weight off.
\end{abstract}

KEY WORDS: obesity, weight management, physical activity

\section{INTRODUCTION}

This article is written in response to an accompanying article in this volume that provides a critique of the National Weight Control Registry (NWCR). ${ }^{1}$ Our intent is to first provide a brief overview of the NWCR and then to respond to some specific points made in the accompanying article.

This research was supported in part by National Institutes of Health grants DK42850, DK42549, and DK066787 and a grant from the Community Foundation for Southeastern Michigan.

\section{PURPOSE OF THE NWCR}

The NWCR, established in 1993 by Drs. James Hill and Rena Wing, was developed to provide information about individuals who have been successful in long-term weight loss maintenance. We wanted to know whether there are commonalities in how these individuals lost weight or how they maintain their weight loss. Our hope is that by studying these individuals, we can learn about the behaviors that contribute to their success in long-term maintenance of weight loss. We believe that this information can improve the chances of success in those individuals who choose to attempt weight loss and in the design and development of future weight loss programs.

Previous studies of weight loss maintenance had used extremely small samples of weight losers, often drawn from one research or treatment program. ${ }^{2-4}$ We wanted the NWCR to be large enough to provide us with the ability to examine subgroups that differ in their specific approach to weight loss, the amount of weight loss, and the duration of weight loss maintenance.

\section{PARTICIPATION IN THE NWCR}

Individuals who have maintained at least a 30-pound weight loss for at least 1 year are eligible to join the NWCR. Entry is based on self-reported success, but all potential participants are asked to document their weight loss. Most (83\%) participants provide some type of documentation. We contacted the physicians or weight loss counselors of a random subgroup of participants and found that the correlation for current and maximum weight was high (.97), suggesting that participants report their current and maximum weight quite accurately.

Currently, we have over 4800 participants in the NWCR. The Table shows the number of subjects added each year since the establishment of the NWCR. About $77.4 \%$ of the sample is female and about $95.3 \%$ is white. On average, they have lost over 70 pounds and have kept it off almost 6 years. They have reduced from a maximum weight of $104.7 \mathrm{~kg}$ to a current weight of $71.8 \mathrm{~kg}$. Thus, participants in the registry are clearly successful at weight loss maintenance. 
Upon initial entry to the registry, participants receive a packet of questionnaires that ask about their weight history, behaviors and strategies used to lose weight, and behaviors and strategies used to keep weight off. Subjects receive additional questionnaires on a yearly basis, allowing us to examine factors that predict weight maintenance versus weight loss in NWCR participants. The response to our yearly surveys is very high, averaging nearly $80 \%$ at annual follow-ups. This rate is comparable to what is typically observed in other prospective surveys. ${ }^{5}$

\section{RESULTS FROM THE NWCR}

We believe that the NWCR has provided important information about the process of weight loss and weight loss maintenance in successful weight losers. We have published many peer-reviewed publications from data obtained from the NWCR. ${ }^{6-20}$ The articles provide information about the behaviors associated with success and, thus, may help people who desire to lose weight be more successful. Some of the highlights of these articles include the following.

\section{Weight Loss versus Weight Loss Maintenance}

One of the most important findings from the NWCR is that the vast majority of members had tried previously to lose weight, unsuccessfully. The fact that they were successful this time (while having been unsuccessful before) should give hope to others attempting weight loss. We found that these individuals used many different approaches to weight loss. The only similarity among participants in how they lost weight was that they used both diet and physical activity. Less than $10 \%$ of NWCR participants lost weight with diet alone and almost none with physical activity alone. However, they used different types of dietary approaches, indicating that people can be successful with different approaches to weight loss

Table. Annual Number of Subjects Enrolled in the National Weight Control Registry

\begin{tabular}{cc}
\hline Year of Enrollment & Number of Subjects \\
\hline 1993 & 92 \\
\hline 1994 & 426 \\
\hline 1995 & 401 \\
\hline 1996 & 1031 \\
\hline 1997 & 268 \\
\hline 1998 & 783 \\
\hline 1999 & 318 \\
\hline 2000 & 317 \\
\hline 2001 & 358 \\
\hline 2002 & 369 \\
\hline 2003 & 385 \\
\hline 2004 & 418 \\
\hline Total & 4820 \\
\hline
\end{tabular}

\section{Similarities in Keeping Weight Off}

In contrast to the diversity of approaches used for weight loss, we find certain commonalities in the approaches for weight loss maintenance. When asked about their current eating and exercise habits, we find that registry participants report consuming a low-calorie, low-fat diet. Almost $80 \%$ state that they consume breakfast every day. Moreover, these individuals report high levels of physical activity, approximating an hour a day of physical activity. Although they do many different forms of activity, walking is the most common activity. Most report weighing themselves on a daily basis and continue to be mindful of their diet and physical activity.

\section{Resting Metabolic Rate}

It is not clear to what extent metabolic versus behavioral factors contribute to the difficulty in weight loss maintenance. To address this, we have examined resting metabolic rate (RMR) in a random group of NWCR members. These individuals were compared with others who were the same age, gender, and weight but did not have a history of obesity. We found that RMR, when expressed in relation to fat-free mass, was not different in NWCR members compared with individuals who had never been obese.

\section{Variables Associated with Continued Weight Loss Maintenance}

We continue to follow registry members over time and, thus far, have examined some of the variables associated with continued weight loss maintenance versus regain over 1 to 2 years (articles examining longer follow-up intervals are in progress). We find that those who maintain their weight loss report better maintenance of their behaviors, including their physical activity; their low-calorie, low-fat eating style; and their dietary restraint. We recently reported that those participants who maintain a consistent diet plan on weekdays and weekends (and on holidays versus nonholidays) are best able to maintain their weight loss. Moreover, the longer one has maintained weight loss, the better the chances of continuing to maintain it! This, again, is a positive message for weight losers because it suggests that each year of weight loss maintenance improves the odds of continued maintenance.

\section{SUBSEQUENT RESEARCH BASED ON THE NWCR}

Findings from the NWCR have also been important in stimulating additional research related to weight loss maintenance. For example, as noted above, registry members report high levels of physical activity-far higher than what is usually recommended in weight loss programs. To determine whether it is feasible and helpful to recommend these high levels of exercise in weight loss programs, Jeffery et al conducted a randomized clinical trial comparing the effects 
of prescribing moderate $(1000 \mathrm{kcal} /$ week $)$ or high $(2500 \mathrm{kcal} /$ week) levels of physical activity to overweight participants. ${ }^{21}$ Their study showed that the high exercise prescription was associated with better weight loss maintenance at 12 and 18 months. Recently, the Institute of Medicine recommended these higher exercise goals for weight loss maintenance. Other studies are currently under way to examine the effectiveness of teaching NWCR strategies to others trying to maintain their weight and comparing successful weight loss maintainers with never-overweight controls. Thus, the NWCR has also been helpful in stimulating additional research related to weight loss maintenance.

\section{SPECIFIC RESPONSE TO THE CRITIQUE OF THE NWCR}

The article included in this journal critiques the NWCR in three general areas':

1. The registry inaccurately estimates the prevalence of successful weight loss.

2. "There is inconsistency in the standards used to enroll subjects in the registry."

3. The registry "does not support greater optimism about the human potential for successful long-term weight loss."

We respond to each of these critiques as follows.

The registry inaccurately estimates the prevalence of successful weight loss.

Most of the critique addresses problems with using the NWCR to estimate the prevalence of success in weight loss maintenance. Unfortunately, the authors of the critique fail to recognize that the NWCR is not a prevalence study; the NWCR does not and cannot address the prevalence of success in weight loss maintenance in the general population. We have never made any attempt to use our data for this purpose.

Although the NWCR cannot address the prevalence of success in weight loss maintenance in the general public, other studies can. The authors of the critique state that $95 \%$ of people who lose weight regain it within 3 years, yet no reference is provided to back up this statement. This statement, which is commonly cited in the media, comes from a 1959 publication by Stunkard and McLauren-Hume ${ }^{22}$ and was based on a study of only 100 patients. Although this result may have represented the state of the art as of 1959, our treatments for obesity have, fortunately, improved since that time.

To estimate the degree of success in long-term weight loss maintenance, it is important to first define success. Obesity experts realize that it is not feasible for many obese individuals to reach and maintain a body mass index (BMI) $\leq 25 \mathrm{~kg} / \mathrm{m}^{2}$ (ie, the healthy range for BMI). For example, the weight management guidelines from the National Institutes of Health state that a reasonable goal for weight loss in obese individuals is to lose 5 to $10 \%$ their body weight. ${ }^{23}$ Evidence is provided in this document that such a weight loss is associated with clear improvements in risk factors for diabetes and heart disease. We conducted a random digit dial national telephone survey in 1999 to assess the prevalence of a $10 \%$ weight loss in those who had attempted weight loss using criteria similar to those used in the registry. ${ }^{23}$ We found that about $20 \%$ of overweight individuals $(\mathrm{N}=228)$ were successful in achieving and maintaining at least a $10 \%$ weight loss for at least 1 year. Moreover, we examined the behaviors of these successful weight loss maintainers and found that they, like NWCR members, reported high amounts of physical activity and a low-fat eating style. Thus, although the NWCR is not a prevalence study and the members are selfselected, the behaviors they report appear to be similar to those seen in nationally representative samples of successful weight loss maintainers.

It is still clear that the majority of people who lose weight regain that weight. However, we have made major advances in setting more reasonable goals for weight loss and in helping people achieve and maintain weight loss in the range of 5 to $10 \%$ of body weight. The statement that $95 \%$ of people who lose weight gain it back is no longer relevant and is not helpful to those who decide to lose weight to improve their health.

"There is inconsistency in the standards used to enroll subjects in the registry."

The authors of the critique state that the standards for including subjects in the registry are inconsistent. In fact, our criteria are clear and have not changed since 1993. Individuals are eligible to join the NWCR if they have maintained at least a 30 -pound weight loss for at least 1 year and are $\geq 18$ years old.

We were also criticized for not expanding the number of subjects in the NWCR over time. Although we are not necessarily actively working to expand the number of subjects in the NWCR, this number has increased each year. The Table shows the number of participants added to the NWCR each year. This has allowed us recently to conduct an analysis to see how the behaviors of individuals entering the NWCR have changed over the years. As might be expected, we have seen an increase in the number of subjects reporting that they are following a low-carbohydrate diet, but this number still remains a very small percentage of total NWCR participants.

The authors of the critique state that obesity experts consider that individuals who have maintained a weight loss for 5 years have been cured. This is, in fact, not true, and obesity experts recognize that obese individuals are never cured, no matter how long they maintain a weight loss. ${ }^{24} \mathrm{We}$ find that although NWCR participants report that maintaining their successful weight loss gets a little easier over time, they still have to work hard to keep weight off even 15 to 20 years after losing weight. 
The registry "does not support greater optimism about the human potential for successful long-term weight loss."

The authors of the critique conclude that the results of the NWCR do not support an optimistic view of people's ability to lose weight and keep it off. In particular, we are criticized that "the registry deludes health professionals into believing that permanent weight loss is a realistic and achievable goal for many of their patients" and that "the data support continued pessimism about the potential success of permanent weight loss for the majority of obese individuals." Obviously, the authors of this critique have a strong point of view about the futility of trying to lose weight and think that the NWCR encourages people to try to lose weight. That is not at all the intent of the registry. We have never implied that people can or should lose weight. Rather, we have simply captured the characteristics of those who do succeed. Our hope is that the results of the NWCR can help people who do decide to lose weight be more successful. Other organizations, such as the North American Association for the Study of Obesity and The American Heart Association, have made a strong case for the importance of weight loss in those who are obese, and the authors of the critique themselves point out that a large part of the American public is attempting weight loss at any given point in time. We hope that the results from the NWCR can help those who do try to lose weight be more successful in achieving and maintaining a healthful weight loss.

Finally, it is very interesting that the authors of the NWCR critique state that "permanent weight loss may be achievable if a person is willing to totally restructure behavior patterns in relation to food and activity." This, in fact, is a major finding of the NWCR. To be successful in achieving and maintaining a significant weight loss, this is essential. We hope that the NWCR provides some help for people in how to do this.

\section{IMPLICATIONS FOR RESEARCH, PRACTICE, AND POLICY MAKING}

The NWCR is not a random sample of the population; therefore, the results cannot be generalized to the entire population of people who attempt weight loss. The best use of these results is to evaluate, in prospective research studies, whether the behaviors demonstrated by NWCR participants will be effective in increasing weight loss maintenance in others attempting weight loss.

\section{ACKNOWLEDGMENTS}

This research was supported in part by National Institutes of Health grants DK42850, DK42549, and DK066787 and a grant from the Community Foundation for Southeastern
Michigan. We thank the many participants in the NWCR for their participation in this research.

\section{REFERENCES}

1. Ikeda J, Amy NK, Ernsberger P, et al. The National Weight Control Registry: a critique. J Nutr Educ Behav. 2005;37:203-205.

2. Colvin RH, Olson SB. Winners revisited: an 18-month follow-up of our successful weight losers. Addict Behav. 1984;9:305-306.

3. Kayman S, Bruvold W, Stern JS. Maintenance and relapse after weight loss in women: behavioral aspects. Am J Clin Nutr. 1990;52:800-807.

4. Dohm FA, Beattie JA, Aibel C, Striegel-Moore RH. Factors differentiating women and men who successfully maintain weight loss from women and men who do not.J Clin Psychol. 2001;57:105-117.

5. Kendall O, Lipskie T, MacEachern S. Canadian health surveys, 19501997. Chronic Dis Can. 1997;18:70-90.

6. Klem ML, Wing RR, McGuire MT, Seagle HM, Hill JO. A descriprive study of individuals successful at long-term maintenance of substantial weight loss. Am J Clin Nutr. 1997;66:239-246.

7. Shick SM, Wing RR, Klem ML, McGuire MT, Hill JO, Seagle H. Persons successful at long-term weight loss and maintenance continue to consume a low calorie, low fat diet. J Am Diet Assoc. 1998;98:408-413.

8. McGuire MT, Wing RR, Klem ML, Seagle HM, Hill JO. Long-term maintenance of weight loss: do people who lose weight through various weight loss methods use different behaviors to maintain their weight? Int J Obes. 1998;22:572-577.

9. Klem ML, Wing RR, McGuire MT, Seagle HM, Hill JO. Psychological symptoms in individuals successful at long-term maintenance of weight loss. Health Psychol. 1998;17:336-345.

10. Wyatt HR, Grunwald GK, Seagle HM, et al. Resting energy expenditure in reduced-obese subjects in the National Weight Control Registry. Am J Clin Nutr. 1999;69:1189-1193.

11. McGuire MT, Wing RR, Klem ML, Lang W, Hill JO. What predicts weight regain among a group of successful weight losers? J Consult Clin Psychol. 1999;67:177-185

12. McGuire MT, Wing RR, Klem ML, Hill JO.The behavioral characteristics of individuals who lose weight unintentionally. Obes Res. 1999;7:485-490.

13. McGuire MT, Wing RR, Klem ML, Lang W, Hill JO. Behavioral strategies of individuals who have maintained long-term weight losses. Obes Res. 1999;7:334-341.

14. Klem ML, Wing RR, Chang CH, et al. A case-control study of successful maintenance of a substantial weight loss: individuals who lost weight through surgery versus those who lost weight through nonsurgical means. Int J Obes. 2000;24:573-579.

15. Klem ML, Wing RR, Lang W, McGuire MT, Hill JO. Does weight loss maintenance become easier over time? Obes Res. 2000;8:438-442.

16. Wing R, Hill JO. Successful weight maintenance. Annu Rev Nutr. 2001;21:323-341.

17. Wyatt HR, Grunwald GK, Mosca CL, Klem ML, Wing RR, Hill JO. Long-term weight loss and breakfast in subjects in the National Weight Control Registry. Obes Res. 2002;10:78-82.

18. Phelan S, Hill JO, Lang W, Dibello JR, Wing RR. Recovery from relapse among successful weight maintainers. Am J Clin Nutr. 2003;78:1079-84. 
19. Gorin AA, Phelan S, Hill JO, Wing RR. Medical triggers are associated with better short- and long-term weight loss outcomes. Prev Med. 2004;39:612-616.

20. Del Parigi A, Chen K, Salbe AD, et al. Persistency of obese-like neural activity in recovered obese in response to a meal. Int J Obes. 2004; 28:370-377.

21. Jeffery RW, Wing RR, Sherwood NE, Tate DF. Physical activity and weight loss: does prescribing higher physical activity goals improve outcome? Am J Clin Nutr. 2003;78:684-689.
22. Stunkard A, McLauren-Hume $M$. The results of treatment for obesity: a review of the literature and report of a series. Arch Intern Med. 1959;103:79-85.

23. McGuire MT, Wing RR, Hill JO.The prevalence of weight loss maintenance among American adults. Int J Obes. 1999;23:1314-1319.

24. National Institutes of Health. Clinical guidelines on the identification, evaluation, and treatment of overweight and obesity in adults-the Evidence Report. Obes Res. 1998;6(Suppl 2):51S-210S. 